\title{
The Moral Career of 'Outmates': Towards a History of Manufactured Mental Disorders in Post-Socialist China
}

\author{
HARRY YI-JUI WU * \\ Medical Ethics and Humanities Unit, Li Ka Shing Faculty of Medicine, \\ The University of Hong Kong, 21 Sassoon Road, Hong Kong SAR
}

\begin{abstract}
This study focuses on 'manufactured mentally ill' (bei jingshenbing, 被精神病) individuals in post-socialist China. In Chinese society, bei jingshenbing is a neologistic catchphrase that refers to someone who has been misidentified as exhibiting symptoms of mental illness and has been admitted to a mental hospital. Specifically, it refers to those individuals who were subjected to unnecessary psychiatric treatment during the first decade of the twenty-first century. Based on archival analysis and ethnographic fieldwork, this study addresses the ways in which the voices of bei jingshenbing victims and those who support them reveal China's experiences with psychiatric modernity. It also discusses the active role of these individuals in knowledge production, medical policymaking, and the implications for reforming the psychiatric and mental health systems in post-socialist China.
\end{abstract}

Keywords: Bei jingshenbing, China, Co-production of knowledge, Mental health law, Patient activism, Psychiatry

\section{Introduction}

After more than two decades of a painstaking legislative process, the Mental Health Law was finally administered in China on 1 May 2013. Many hoped that adopting this law at the state level would not only adjust the potential political abuses of psychiatry, but would also popularise community mental health services, regulate the professional and disciplinary functions of psychiatric science and provide legal grounds for appropriate psychiatric treatments. ${ }^{1}$ Before this law was administered, the neologistic catchphrase bei jingshenbing (被精神病), which referred to someone who had been misidentified as exhibiting symptoms of mental illness and admitted to a mental hospital out of either humanitarian or malicious intent, suddenly became a media buzzword both online and in

\footnotetext{
* Email address for correspondence: hyjw@hku.hk
}

The author thanks Miss Yang Xi of the University of Hong Kong, Ms Liu Lin of Peking University and Miss Lee Xing Mei of Nanyang Technological University for their technical assistance during the course of data collection. In addition, this study could not have been conducted without the help of all interviewees appearing in the article, to whom the author owes an immense debt of gratitude. Finally, thanks are due to the three anonymous reviewers for their helpful suggestions.

\footnotetext{
${ }^{1}$ Mara Hvistendahl, 'A New Dawn for Mental Health', Science, 339 (2012), 506-7.
} 
the press. This buzzword even made its way into numerous popular outlets, including novels and essay collections authored by public intellectuals. ${ }^{2}$ Although unlawful or unjustifiable psychiatric admissions have not been uncommon throughout contemporary Chinese history, the specific expression bei jingshenbing did not emerge until the twentyfirst century. Some considered these admissions psychiatric abuse; others viewed them as flawed practices resulting from poor regulation.

Based on historical accounts collected from the Beijing Municipal Archives, historical and contemporary Chinese medical periodicals, and oral interviews conducted during fieldwork at multiple sites in China with psychiatrists, lawyers, human rights activists and individuals who experienced bei jingshenbing, this study portrays the various (mis)appropriations of psychiatry from historical and contemporary perspectives. It also addresses the implications of this phenomenon for the reform of modern psychiatry and mental health in China. More generally, this paper echoes Roy Porter's call for reconstructing the people's history of suffering and restoring the 'human face' of medical history ${ }^{3}$ by shedding light on the still under-explored psychiatric developments in the Chinese context.

Patients with mental disorders have historically gone untreated or have been poorly managed due to the lack of psychiatric facilities and the tradition of home custody in China. However, the situation has recently changed due to the country's rapidly transforming economy, social structure and medical culture, in addition to the restructuring of family dynamics. The growth of China's GDP, substantiation of the health system, and institutionalisation of psychiatry in recent decades were expected to improve care and treatment for underprivileged individuals. Yet, in its current state, mental health care differs from its original aims. Three decades after the initial call for the development of psychiatry after its long suspension from the mid-1960s to the late-1970s, the current proprofit mental hospitals in China have indeed become a battlefield for various conflicts of interest.

Since 2008, the rapid spread of bei jingshenbing in Chinese society has reflected the disjunctive acceleration of various types of modernity in relation to capitalisation, social transformation and political reformation. Individuals deemed mentally ill are involuntarily admitted to psychiatric hospitals not only to help them receive treatment and care, but also to pacify family conflicts and maintain the public order. In this piece, I borrow the concept of 'moral careers' introduced by Erving Goffman - who depicts how inmates committed to a mental hospital learn to cope with the treatment provided by asylum staff - to analyse how individuals who have been discharged from hospitals (and those who support them) defend their own rights. ${ }^{4}$ Yet, by collecting testimonies from beyond hospital walls, this preliminary exploration differs from Goffman's. Specifically, it combines historical analysis with ethnographic fieldwork to illuminate a still largely unknown phenomenon.

\footnotetext{
${ }^{2}$ For example, at least four essays have mentioned the use of bei jingshenbingin social critic Li Chengpeng's prominent essay collection. See Chengpeng Li, As We All Know (Taipei: INK Literary Monthly Publishing, 2013). Furthermore, in Guangzhong Chen's novel Shengshi: Zhongghuo 2013 Nian (Hong Kong: Oxford University Press, 2009), a character is admitted to a psychiatric ward after criticising the Chinese Communist Party.

${ }^{3}$ Porter expressed this a number of times. For example, see Roy Porter, A Social History of Madness (London: Weidenfeld \& Nicolson, 1987); Roy Porter, The Faber Book of Madness (London: Faber \& Faber, 1991); and Roy Porter, Madmen: A Social History of Madhouses, Mad Doctors \& Lunatics (Stroud: Tempus, 2004).

${ }^{4}$ Erving Goffman, Asylums: Essays on the Social Situation of Mental Patients and Other Inmates, 1st edn (Anchor, A277; Garden City, NY: Anchor Books, 1961).
} 
The article begins with an overview of China's recent modernity experiences as they relate to psychiatry and mental health, in particular, with regard to unjustifiable psychiatric admissions and new diagnostic classification systems. It then turns to the emergence of bei jingshenbing in its broader social and medical context. Finally, inspired by Steven Epstein's bookImpure Science on AIDS, activism and the concept of knowledge coproduction in the field of science and technology studies, it critically examines the activities of its informants, particularly the Shenzhen-based private legal consultation company Equity and Justice Initiative (EJI) ${ }^{5}$ Of especial interest is the way in which these individuals, including ex-inmates and their defenders, influence policymaking and help disseminate lay knowledge about psychiatry amongst medical professionals. By collecting those unheard voices, this work provides insight 'from below' into the specific changes China's medical community has experienced - and the challenges it continues to face.

\section{The Place of Psychiatry in China's Modernity Experiences}

The emergence of bei jingshenbing in post-socialist China stems from a unique historical moment. Discussing the differences between western and Chinese mental health, historians Helaine Selin and Hugh Shapiro argue that Chinese medicine cannot be understood in western terms. ${ }^{6}$ Bei jingshenbing is not merely an expression referring to psychiatric abuse as described in western psychiatric accounts. It can only be comprehended when placed in the disjunctively accelerated medical and economic modernity that is unique to post-socialist China. In addition to advances in medical infrastructure, reforms in the legal system, and the remodelling of psychiatry as a distinct medical speciality, China's recent economic achievements have also had considerable social and political consequences. ${ }^{7}$ These include widening inequalities among regions, damage to the environment, increasing conflicts between communities, and the loss of job security and social welfare (notably among workers of the state enterprises). Mental illness is one of these consequences. The emergence of bei jingshenbing examined here reflects the moral conflicts and emotional struggles created by China's rapid and extreme modernisation.

Bei jingshenbing became a buzzword in public discourse towards the end of the first decade of the twenty-first century for several reasons. Apart from the possible political abuses of psychiatry, which had been suspected with or without direct evidence, the term arose amidst mistrust between doctors and patients, the restructuring of kinship ties within Chinese families and the development of individualistic approaches. At the time, Chinese psychiatry was seeking to become an autonomous discipline and to help expedite the government's campaign against corruption. The deterioration of doctorpatient relationships in China can only be further understood in the context of migrant exclusion during urbanisation, the unequal allocation of medical resources and the increase

\footnotetext{
${ }^{5}$ See Steven Epstein, Impure Science: Aids, Activism, and the Politics of Knowledge, Medicine and Society (Berkeley: University of California Press, 1996); Sheila Jasanoff, States of Knowledge: The Co-Production of Science and Social Order, International Library of Sociology (London; New York: Routledge, 2004), xii.

${ }^{6}$ Helaine Selin, Hugh Shapiro, and Springerlink (Online Service), Medicine across Cultures: History and Practice of Medicine in Non-Western Cultures, Science Across Cultures (Dordrecht; Boston: Kluwer Academic Publishers, 2003), xxiv.

${ }^{7}$ Elizabeth J. Perry and Mark Selden, Chinese Society: Change, Conflict and Resistance, 3rd edn, Asia's Transformations (London; New York: Routledge, 2010), xvii.
} 
of chronic diseases, factors contrary to the false hope instituted by the expanding neoliberal medical market that accompanied the unique medical-help-seeking culture. ${ }^{8}$

Despite efforts from the authorities to improve the infrastructure of psychiatric services since the beginning of the twenty-first century, ${ }^{9}$ an anti-medical sentiment has formed among patient groups and the general population. From the perspective of the recent anti-corruption campaign, the heated discussion surrounding bei jingshenbing as a media buzzword, in a society becoming more wired and Internet-driven than its western counterparts, reflects a deliberate loosening of the control over public opinion, making salient the inappropriate guanxi (relationships) that local public servants share with proprofit hospitals and bribing families. ${ }^{10}$ The voices included below are significant as to the transformation of psychiatry and mental health in the context of China's modernity experience. They can only be understood against the background of this country's unique psychiatric past.

\section{Unjustifiable Psychiatric Admissions in Modern Chinese History}

It has been argued that in pre-psychiatry China, 'madness' was considered a physical ailment like any other corporeal disease. Medical interventions for it were no different from those of other treatments. The management of extreme forms of insane behaviour was the responsibility of non-medical judicial or policing institutions. ${ }^{11}$ Even in contemporary China, suicidal attempts are not treated as psychiatric problems. Suicide is seen as a quest for justice among sane individuals, a viewpoint backed by both ethnographical and epidemiological accounts. ${ }^{12}$ These examples suggest that medicine has played a less significant role in treating extreme psychiatric behaviour in China than it has elsewhere.

Psychiatry is a young medical speciality in the Chinese-speaking world: indeed, it was not an autonomous speciality until the second half of the twentieth century. According to anthropologist Nancy Chen's analysis, the development of psychiatry in this country can be divided into three periods: missionary, Maoist and post-Maoist. ${ }^{13}$ Missionaries and colonial enterprises introduced psychiatry to Chinese cities between the mid-nineteenth and early twentieth centuries, either as part of the modernisation process or as a form of benevolent charity work. In 1898, American medical missionary John Kerr (1821-1901) established a hospital in Canton for mentally ill patients; this was the first psychiatric

\footnotetext{
${ }^{8}$ Harry Yi-Jui Wu, 'Deep Reflection Needed on China's Medical-Help-Seeking Culture', The Lancet, 381, 9863 (2013), e2.

${ }^{9}$ For example, the '686 Project' was launched in 2004 after the SARS epidemic to strengthen the public mental health infrastructure by scaling up community mental health services throughout the country. The third psychiatric epidemiology study of mental disorders at the national scale commenced in 2011 with the Ministry of Science and Technology and Ministry of Health lending RMB24.98 million in support. There have also been calls for national board specialist training systems.

${ }^{10}$ In China, guanxi refers to the system of social networks and influential relationships which are critical in facilitating business and other social contracts.

${ }^{11}$ Fabien Simonis, 'Medicaments and persuasion: medical therapies for madness in nineteenth-century China', in Howard Chiang (ed.), Psychiatry and Chinese History, Studies for the Society for the Social History of Medicine, vol. 21 (London: Pickering \& Chatto, 2014), 55-70.

12 Fei Wu, 'Suicide, a modern problem in china', in Arthur Kleinman (ed.), Deep China: The Moral Life of the Person (2011), 213-36; Michael R. Phillips et al., 'Assessing Depressive Symptoms in Persons Who Die of Suicide in Mainland China', Journal of Affective Disorders, 98, 1-2 (2007), 73-82.

${ }^{13}$ Nancy Chen, 'Translating psychiatry and mental health in twentieth-century China', in Lydia He Liu (ed.), Tokens of Exchange: The Problem of Translation in Global Circulations (Durham, N.C.; London: Duke University Press, 1999).
} 
hospital in China. ${ }^{14}$ In Shanghai, those considered insane were first admitted to St Joseph's Hospice, an asylum-like institution established by a Catholic diocese in the 1930s. ${ }^{15}$ Regardless of the theories and practices surrounding mental illness in traditional Chinese medicine, these institutions reflected the sporadic diffusion of western medicine in Chinese-speaking areas. The number of sick beds and the scale of this service were not sufficient to manage the influx of individuals with mental illness during the process of urbanisation in the first half of the twentieth century.

In Republican Beiping (current Beijing) (1912-49), the fengrenyuan (asylum for the insane 疯人院) of the Beijing Police Board, that existed between 1912 and 1941, was used to facilitate the temporary custody of social deviants who were considered insane. Patients were judged mentally ill on the summons filed by police, not on the basis of medical evidence. Without careful evaluation, the police would believe individuals who complained about the violent and disorganised behaviour of their loved ones, if they considered that these individuals posed a physical threat to themselves. One father asked the police to send his ferocious son to the asylum to preserve his family's safety. ${ }^{16}$ One husband institutionalised his wife to calm her down lest she stab herself in the neck in a fit of pique. ${ }^{17}$ After being accused of insanity by strangers following a street quarrel in which they were also beaten up, some ordinary men were admitted to the asylum. ${ }^{18}$ In these cases, the voices of the committed individuals went unheard. The plaintiffs' statements of confession were documented in the police reports. Within the Police Bureau, the fengrenyuan was repeatedly consulted to provide specialists who could attest to whether the arrested individuals were truly insane. Yet the corresponding records show that the asylum employed no medically trained personnel. ${ }^{19}$ Rather, the fengrenyuan was a purely custodial institution established for the purpose of social security. It was not until the reinstitutionalisation of the municipal asylum in 1933, under the administration of the city health authorities and management of the Rockefeller Foundation's China Medical Board, that it undertook a medical function. ${ }^{20}$ This marked a turning point in the modern history of China: 'madness' became medicalised.

Despite the medicalisation of madness, the everyday attitudes of the Chinese people towards insanity appeared to be mixed in relation to the causes and cures for mentally unruly behaviour. Chinese men and women were not significantly influenced by the influx of western psychological thought and the establishment of western hospitals, with the vast majority of the lower classes still tending to rely upon traditional modes of therapeutic practice. ${ }^{21}$ After the establishment of the People's Republic of China in 1949, disputes in Beijing over custody of the insane continued to loom large among the police, civil administration and medical sector. As the population grew, more appeals emerged that called for the construction of facilities, not only for security reasons but also for

\footnotetext{
${ }^{14}$ Peter Szto, 'Psychiatric space and design antecedents: the John G. Kerr refuge for the insane', in Howard Chiang (ed.), Psychiatry and Chinese History (London: Pickering \& Chatto, 2014), 71-90.

15 C. Hart Westbrook, 'Psychiatry and Mental Hygiene in Shanghai: Historical Sketch', American Journal of Psychiatry, 110 (1953), 301-6.

16 Beijing Municipal Archives. Ref. No.: J181-018-02518.

${ }^{17}$ Ibid., Ref. No.: J181-018-09598.

18 Ibid., Ref. No.: J181-021-05178.

${ }^{19}$ Ibid., Ref. No.: J181-018-07345.

${ }^{20}$ See Hugh Shapiro, 'The View from a Chinese Asylum: Defining Madness in 1930s Peking' (PhD dissertation, Harvard University, 1995).

${ }^{21}$ Emily Lauren Baum, 'Spit, Chains, and Hospital Beds: A History of Madness in Republican Beijing, 1912-38' (PhD dissertation, University of California, San Diego, 2013).
} 
medical treatment. Statistics indicate that, in October 1954, 640 sick beds were taken care of by seven medical doctors and 205 personnel at Beijing Psychiatric Hospital. ${ }^{22}$ The facilities in the hospital were also improved to a considerable degree in order to better care for its residents. However, in the meantime, Beijing conducted a citywide survey concerning the total number of mental patients. Although the survey method is unknown, it was reported that there were 808 mental patients in the city. Among them, 101 individuals were seen as threats to the city's public order. Surveyors concluded that there might be more than 1000 individuals in rural Beijing requiring psychiatric care. Under an overhaul of the Department of Civil Affairs, the Head of the Department of Health, Yen Jingqing, then asked the People's Government of Beijing to screen out those who should be discharged by the hospital and were suitable for home care.

The selection of patients became more important during certain specific dates, such as during the National Day of China. Such a tactic, it was believed, would maintain the appearance of the city. ${ }^{23}$ Moreover, in Beijing the capacities of psychiatric hospitals were limited. Despite the heated discussion among various sectors - the Police department, the Department of Civil Affairs, the Department of Health - the consensus remained that home was still the destination of choice for the mentally ill. Hospital personnel and the police were mobilised by the authorities to persuade families to take inmates home after various forms and lengths of custody, although this was not completely successful. Before the suspension of psychiatry in China during the 1960s and '70s, appeals were made to establish specialist institutions for the growing mentally ill population. However, due to a lack of specialists in psychiatry, insufficient financial resources and the vague division of authority and responsibility among the three sectors, the services of the original mental asylums remained inadequate. ${ }^{24}$

Preferred therapeutic models also went through various changes. During the Great Leap Forward (1958-61), a socialist model of mental hygiene, embracing Soviet psychological theories and practice, was established to replace the services provided by institutions put forth by western missionaries. For example, a rapid combined treatment was employed in a government-supported campaign to treat neurasthenia in $1959 .{ }^{25}$ However, newly constructed institutions did not fully replicate the Soviet Union's extreme use of 'penal psychiatry' for the punishment or control of political dissidents. Psychiatrists, influenced by Pavlovian theories, believed that patients' symptoms could be improved and even reformed or cured through activity and work. ${ }^{26}$

\footnotetext{
22 Beijing Municipal Archives, Ref. No. 002-006-00284.

${ }^{23}$ In October 1954, Beijing attempted to send psychiatric patients who were deemed harmful to the public security of the city and uncontrollable at its psychiatric hospital to Tianjin, a port city conveniently connecting the capital. As a result, complaints were filed by Tianjin City. In the latter half of the 1950s, suggestions were made to build a hospital under Civil Affairs. Before the hospital was completed, a solution was reached, where, each year before the National Day, a quota of patents with milder symptoms in the hospital should be replaced with those who were more menacing. Discharged patients should then be sent to the care of Civil Affairs (Beijing Municipal Archives, Ref. No. 002-011-00035).

${ }^{24}$ Op. cit. (note 22) 12 November 1954. The Beijing People's Government assumed it was illegal for the police sector to admit psychiatric patients. However, before an official institution was established, the internal affairs and health authorities could temporarily share such work with the police.

${ }^{25}$ Hugh Shapiro, 'Neurasthenia and the Assimilation of Nerves into China' (unpublished paper, 1993).

${ }^{26}$ Nancy Chen, op. cit. (note 13); Robert Chin and Ai-Li S. Chin, Psychological Research in Communist China, 1949-66 (Cambridge, MA: MIT Press, 1969), xii.
} 


\section{Bei Jingshenbing and the Issue of Psychiatric Classification}

During the initial phase of the 'Reform and Opening Up' period in the early 1980s, China experienced external pressures to adopt western psychiatric theories and methods, all the while witnessing a burgeoning of research related to the specifically Chinese methods of coping with new mental health concepts. This created an awkward tension between the adoption of effective techniques and resistance against western ideologies. ${ }^{27}$ By the time of the Cultural Revolution (1966-76), mental health issues had long been neglected in China, and psychiatric research had been isolated from international activities. ${ }^{28}$ This made China reluctant to help this field achieve world benchmarks for professionalism in psychiatric dialogue. The Chinese Classification of Mental Disorders (CCMD), which first appeared in 1979, was a diagnostic system initially proposed to account for diseases observed only in the Chinese context and eventually to integrate with the International Classification of Diseases, the diagnostic system developed by the World Health Organisation (WHO). ${ }^{29}$

Despite the rapid development of China's own diagnostic classification system, grey areas remain with regard to interpreting mental symptoms both cross-culturally and within China's state discourse. ${ }^{30}$ For example, petitioners who seek fair treatment in the capital city have been labelled 'pianzhi' (paranoid), putting these individuals at risk of involuntary hospitalisation. Researchers have likewise pointed out that the definition of certain mental disorders such as 'travel psychoses' in the CCMD-2 are unique to China's social and cultural setting. ${ }^{31}$ Not unlike the ideologically based psychiatric taxonomy developed in Soviet Russia, the Chinese classifications reflect the urgent necessity for a newly imposed scientific instrument to match the local context.

The recent emergence of bei jingshenbing is characteristic of the central state's discourse with regard to the need for order and normalcy as China aspires to connect with international values. In many reported cases, petitioners considered by police to be pianzhi (paranoid) end up being committed for 'pianzhixing jingshen fenlie zheng' (delusional schizophrenia) by psychiatrists who are not board certified. In addition, evidence has surfaced that the rise of pragmatism and mercenary behaviour has brought on an increasingly individualistic middle class in addition to rising public sector expenditures on psychiatric services. ${ }^{32}$ Unethical hospitalisation often occurs due to the guanxi (business relationships) shared by desperate families, complex security structures, corrupt local governments, poorly developed judicial systems and profit-making hospitals. ${ }^{33}$

\footnotetext{
27 Veronica Pearson, Mental Health Care in China (London: Gaskell, 1995).

${ }^{28}$ Much remains to be explored on psychiatry during the Cultural Revolution, from 1966 to 1976, during which time psychiatric research was suspended and psychiatric services were abused for political purposes.

29 The first CCMD appeared in 1979. A revised classification, the CCMD-1, was made available in 1981 and further modified in 1984 (CCMD-2-R). The CCMD-3 was published in 2001. See Sing, 'From Diversity to Unity. The Classification of Mental Disorders in 21st Century China,' Psychiatric Clinics of North America, 24, 3 (2001), 421-31.

${ }^{30}$ Compared with the DSM system, the ICD is favoured in China as it has been developed for underdeveloped countries. See Yan-Fang Chen, 'Chinese Classification of Mental Disorders (CCMD-3): Towards Integration in International Classification', Psychopathology, 35 (2002), 171-5; Sing Lee, 'Cultures in Psychiatric Nosology: The CCMD-2-R and International Classification of Mental Disorders', Culture, Medicine and Psychiatry, 20, 4 (1996), 421-72.

${ }^{31}$ Sing Lee, 'Higher Earnings, Bursting Trains and Exhausted Bodies: The Creation of Travelling Psychosis in Post-Reform Chinas', Social Science \& Medicine, 47, 9 (1998), 1247-61.

${ }^{32}$ Huang Xuetao, interviewed by the author, 5 February 2013, Shenzhen, China.

${ }^{33}$ Liu Wei, interviewed by the author, 7 March 2013, Hong Kong SAR, China.
} 
For the last three decades, China has carried out epidemiological research to define the scope of its psychiatric service provision and develop related mental health policies. ${ }^{34}$ Following the method developed by the WHO, studies conducted in 1982 and 1983 using both ICD and CCMD-2 disease classifications claimed that the time-point and lifetime prevalence of all mental disorders are 11.18 per cent and 13.47 per cent, respectively. ${ }^{35}$ Research has concluded that the prevalence of major psychiatric disorders in China is similar to that of other WHO findings except for depressive disorders, which are much less prevalent. ${ }^{36}$ To encourage the use of ICD systems in both research and the clinical field, the WHO proposed a research centre for disease classification, which was established by Xiehe Hospital in Beijing in $1981 .^{37}$ In addition, to improve China's commitment to building up its public mental health infrastructure, the ' 686 Project' commenced in 2004 to ameliorate community services, improve the professional training of different stakeholders and construct a database of experiences to achieve successful reform. ${ }^{38}$ Although a complete, nationwide epidemiological survey of mental illnesses has not yet been conducted, the figures arrived at more than a decade ago have become the parameters used in most of the official documents and research to estimate the number of individuals in need of psychiatric care in China. These include 17.5 million mentally ill individuals, 8.5 million of whom are said to be schizophrenic. ${ }^{39}$ In addition, despite new studies having been conducted with better epidemiological methods to obtain more accurate statistical numbers, including projects carried out by leading psychiatric institutions in Shanghai and Beijing, the grounds by which mental health policies are administered locally do not always align with this updated research. ${ }^{40}$ For example, the health administration of Zhengzhou was criticised for its 2 per cent mandatory identifying rate for severe psychiatric disorders, which enhanced the risk of misdiagnoses - and therefore the potential for bei jingshenbing. ${ }^{41}$

\footnotetext{
34 Yucun Shen, 'The Significance of Developing Psychiatric Epidemiological Studies', Chinese Journal of Psychiatry, 31, 2 (1998), 67-8.

35 Weixi Zhang, Yucun Shen and Shuran Li, 'Psychiatric Epidemiological Studies in Seven Regions in China', Chinese Journal of Psychiatry, 31, 2 (1998), 69-71.

36 Sing Lee, 'Depression: coming of age in China', in Kleinman (ed.), op. cit. (note 12), 177-212. Anthropologist Arthur Kleinman observes that neurasthenia and depression have identical diagnoses in China. He also points out that the manifestation of neurasthenia in China comprises a considerable array of somatic symptoms. It was not until recently that Chinese psychiatrists gradually stopped using the term 'neurasthenia' in favour of 'depression'. (Kleinman, 'Neurasthenia and Depression: A Study of Somatization and Culture in China', Culture, Medicine, and Psychiatry, 6, 2 (1982), 117-90.

${ }^{37}$ Shen, op. cit. (note 34).

${ }^{38}$ Byron Good and Mary-Jo Delvecchio Good, 'Significance of the 686 Program for China and for Global Mental Health', Shanghai Archives of Psychiary, 24, 3 (2012), 175.

${ }^{39}$ Kam-Shing Yip, Mental Health Service in the People's Republic of China (New York: Nova Science Publisher, 2007).

40 Since 2009, most of the official and journalistic accounts started to sign the figures reported by Shanghai's Mental Health Centre. See Michael R. Phillips et al., 'Prevalence, Treatment, and Associated Disability of Mental Disorders in Four Provinces in China during 2001-05: An Epidemiological Survey.' The Lancet, 373 (9680), 1319. Another large-scale epidemiological study conducted by the Beijing Institute of Mental Health was completed in 2014. For details of recent local and cross-province studies see Yueqin Huang et al. 'Mental health in mainland China', in Dinesh Bhugra et al. (eds), Routledge Handbook of Psychiatry in Asia (Abingdon: Routledge, 2015).

41 'Zhengzhou orders to identify two mentally ill individuals out of 1000', http://news.sina.com.cn/c/2013-10-0 9/094128383609.shtml, 2013 (accessed 15 September 2014).
} 


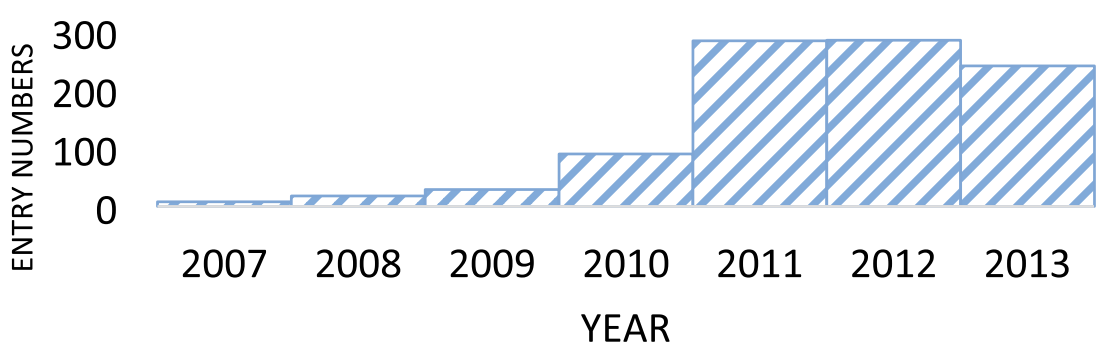

Figure 1: The figure shows proliferation of discussion on bei jingshenbing in 2011 according to the search engine Zhongguo Zhiwang.

\section{Various Pictures of Bei Jingshenbing}

As Figure 1 shows, the growing menace of bei jingshenbing as a media buzzword in the turn-of-the-twenty-first-century Chinese imagination cannot be ignored. It should be redundant to add the character 'bei' in front of 'jingshenbing'. In modern psychiatry, mental disorders are considered valid only once diagnoses are made. Validating mental disorders is therefore a passive action by nature. However, the existence of bei jingshenbing in China is unique not so much because of its generic meaning, but because, as a form of public rhetorical strategy, it reflects various factors that lie outside of psychiatric institutions. This expression has become a byword in contemporary Chinese society, as citizens' fear of being labelled mentally ill in their everyday lives has effectively surpassed their fear of mental illness itself.

To an extent, the emergence of the phrase bei jingshenbing can be attributed to a media incident. Towards the end of the first decade of the twenty-first century, cases of supposedly healthy individuals being unjustifiably committed to psychiatric institutions were reported in droves. These included, among others, petitioners who were sent to hospitals by the police, urban management officers sent for security reasons and family members who were dumped into psychiatric wards over financial disputes. Although the actual expression had been coined two to three years earlier, it was popularised in 2010 when a petitioner named Peng Baoquan was arrested by local police as he attempted to bypass the local judicial system and travel to Beijing to lodge his complaints. He was sent to a local psychiatric hospital for six days, during which time he sent out calls for rescue using a mobile phone, saying that he had been 'bei jingshenbing'. ${ }^{42}$ Peng's case attracted intense public attention and media coverage, and many similar instances were subsequently reported. The expression has been extensively discussed in academic circles ever since.

The popularity of the buzzword rose in 2010, reached its peak in 2012 and then decreased in 2013. Figure 1 (above) shows the number of entries about bei jingshenbing according to the search engine Zhongguo Zhiwang (中国知网). Since the Peng Baoquan case, reports of unjustifiable psychiatric admission have been retrospectively 'diagnosed' as bei jingshenbing. For the past two decades, the fiercest accusations of China's 'political psychiatry' have been put forth by Robin Munro of Human Rights Watch; they include

42 Xuetao Huang, Jiajia Liu and Xiaohu Liu, The Involuntary Commitment System of China: A Critical Analysis (Shenzhen: Equity \& Justice Initiative, 2010). 
the Tiananmen Incident and the abuse of Falun Gong practitioners. ${ }^{43}$ Munro's allegations sparked heated debates among scholars, resulting in two collections of essays published in the Columbia Journal of Asian Law and the Journal of American Psychiatry and Law. ${ }^{4}$ Just like their media coverage, these debates did not last long, as most scholars could only rely on outdated personal experiences and limited correspondence with their acquaintances in China. The context of untenable psychiatric admissions was altered after attempts at reform were made.

Apart from whispers of official abuse, examples of contemporary bei jingshenbing include petitioners who are classified as 'paranoid', family members who are abandoned, and employees who are classified as ill by companies over financial disputes. Similar examples are common throughout China's long history; indeed it can be argued that the culture of medical paternalism and families caring for the mentally ill effectively planted the seeds of bei jingshenbing. ${ }^{45}$ These patterns did not disappear with the professionalisation of psychiatric services in China, resulting in cases where the word of mediators (for example, police and local officials as opposed to professionals or legal guardians) became the main source of symptom-related information. The above shows the crucial importance of delving into the biomedical construction of culturally sensitive disorders in China. ${ }^{46}$

\section{Bei Jingshenbing and the New Mental Health Reform}

China's Mental Health Law was finally passed in 2012 and officially administered on 1 May 2013, heralding a fresh dawn for mental health reform in the country. However, the issue of bei jingshenbing has persisted as a neologistic catchphrase in Chinese society, and it will likely be a long time before the Chinese make substantial inroads into the systematic and reflective understanding of mental wellbeing. ${ }^{47}$ Despite having no medical designation, the term bei jingshenbing has been used frequently in the media in recent years. The government hopes that the adoption of the Mental Health Law will prevent any further growth in the number of bei jingshenbing cases. ${ }^{48}$ Although this issue has been discussed vehemently in the Chinese media, comments made by medical and legal scholars, thus far, have been overly top-down and technical.

\footnotetext{
43 Robin Munro, 'Judicial Psychiatry in China and its Political Abuses', Columbia Journal of Asian Law, 14 (2000), 1-128.

${ }^{44}$ Robin Munro, 'Political Psychiatry in Post-Mao China and its Origins in Cultural Revolution', Journal of American Psychiatry and Law, 30 (2002), 97-106. Sing Lee and Arthur Kleinman, 'Psychiatry in its Political and Professional Contexts: A Response to Robin Munro', Journal of American Psychiatry and Law, 30 (2002), 120-5; Sunny Y. Lu and Viviana B. Galli, 'Psychiatric Abuse of Falun Gong Practitioners in China', ibid., 12630 .

${ }^{45}$ Xiehe Liu, "The Prevention of "Bei-Jingshenbing" and the Reformation of Mental Heath Institution Management', Chinese Mental Health Journal, 26, 2 (2012), 82-3; Nikolas Rose, 'Biological citizenship and its forms', in Everett Zhang, Arthur Kleinman and Weiming Tu (eds), Governance of Life in Chinese Moral Experience: The Quest for an Adequate Life (London and New York: Routledge, 2011), 237-65.

${ }^{46}$ Yicheng Jia, 'Discussion on Mental Disorders Associated with Qigong, Pseudo-Qigong and Falungong', Shanghai Archives of Psychiary, 13, 3 (2001), 172-4; Lee, op. cit. (note 30). More research is needed on the direct and indirect relationships between an increase of these so-called qigong piancha (qigong deviations) in the 1990s and the definition of 'induced psychosis' placed in the Chinese Classification of Mental Disorders-2R in 1994. On these topics, see Yicheng Jia, 'Discussion on Mental Disorders Associated with Qigong, PseudoQigong and Falungong', Shanghai Archives of Psychiary, 13, 3 (2001), 172-4; Lee, op. cit. (note 30).

${ }^{47}$ Liu, op. cit. (note 45).

${ }^{48}$ Hvistendahl, op. cit. (note 1).
} 
The Mental Health Law may mean the advent of standardised psychiatric practice in China, as it is expected by the authorities to help Chinese people gain better access to mental health services. Nevertheless, many have identified the insufficient amount of specialised and quality services, in addition to the general unwillingness of Chinese communities, as major roadblocks for China's efforts to decrease the burden of mental illness. ${ }^{49}$ The adoption of the law, it is hoped, will do more than simply decrease the abuse of involuntary treatment. However, concerns have been raised about the short-term effects on the need for community-based mental health services. ${ }^{50}$ Furthermore, different kinds of public and private stakeholders possess diverse levels of awareness and knowledge about psychiatry. A lack of regulation in the form of a board-certified training system for psychiatrists and other mental health workers, it is feared, might result in the manipulation of terms and concepts. Although the new Mental Health Law states that the diagnostic criteria for mental illness should be regulated according to standards approved by China's Ministry of Health, the Ministry has not yet consented to any diagnostic system that would be suitable for the Chinese social, cultural and medical contexts. It has also failed to coordinate with international classification systems and criteria. At the national level, the as-yet-undefined diagnostic criteria for the certifiably insane could conflict with national security objectives. Sufficient resources are lacking at the local level, and the Mental Health Law remains unable to regulate affairs in areas below the xian, the administrative prefecture under the provincial level.

\section{From Victims to Self-Advocacy Groups: Voices of Bei Jingshenbing}

In addition to the strengthening psychiatric infrastructure that has been provided by both the state and foreign aid, the voices from below must also be considered in order to get a fuller picture of psychiatry and mental health reform in China. These voices include public defenders who have long been focusing on the civil rights of mental patients, patients who have been misidentified as mentally ill, activists who have been disclosing their unjust treatment in mental asylums, as well as service users and 'survivors' who have formed self-advocacy groups and clubhouses to make themselves visible to psychiatric resource providers and policymakers. Based on ethnographic notes and interviews conducted in person and online at multiple sites in China, the following section explores the substantial and symbolic meaning of the public defenders' activities.

Whether these various opinions from below can be considered subaltern narratives is challengeable: indeed they are no longer voices that have been crushed or suppressed. Instead, to some extent, these men and women have actively been trying to influence the public's understanding of psychiatric sciences and policymaking. Contrary to what Erving Goffman depicts in his classic book Asylums, in which most inmates committed to a mental hospital learn to cope with, and eventually depend on, the services of asylum staff, the individuals and groups described in this study speak outside of the asylum with the particular purpose of not only defending their own rights but also achieving the common good of Chinese citizens. ${ }^{51}$ Moreover, the narrators of bei jingshenbing experiences are individuals who have been misdiagnosed or deliberately labelled ill. By making explicit

\footnotetext{
49 Michael R. Phillips et al., 'China's New Mental Health Law: Reframing Involuntary Treatment', Asian Journal of Psychiatry, 170, 6 (2013), 588-91.

${ }^{50}$ Michael R. Phillips, 'Can China's New Mental Health Law Substantially Reduce the Burden of Illness Attributable to Mental Disorders?', The Lancet, 381, 9882 (2013), 1964-6.

${ }^{51}$ Goffman, op. cit. (note 4).
} 
claims through various channels such as putting on skits in the street and publishing official reports, their activities are no longer hidden transcripts but powerful accounts that highlight the flaws of the current mental health system in China.

The Chinese Network for Users and Survivors of Psychiatry (CNUSP) was established in 2012 on the Internet as an anonymous online forum consisting mainly of users and exusers of psychiatric services, social workers, clinical psychologists and lawyers. Behind the network is a non-governmental organisation (NGO) based in Shenzhen, China's first Special Economic Zone. I began to visit Equity and Justice Initiative (EJI) at the end of 2012. The organisation receives funds from domestic and foreign charities. It has not only provided legal aid to victims of bei jingshenbing, but also actively lobbied the revision of drafts of the Mental Health Law. My double background as a clinician and a historian enabled me to win the confidence of the organisation to conduct consultations while observing its 'social organisation' of knowledge. As such, I engaged in participatory observations, which included conducting several semi-structured interviews with EJI members. ${ }^{52}$ In this part of the paper I analyse the social relations among the EJI, psychiatric specialists, the government, other NGOs and their service users. In doing so, I attempt to document a process of knowledge-making from the standpoint of the informants' everyday lives, in the hopes of demystifying the power relations among them and ultimately contribute to possible intervention methods.

Huang Xuetao, founder of EJI, began to attend to cases of unjustifiable psychiatric commitment in 2006. At the time, she was a defence attorney for a woman who was deceived by a family member and admitted to a psychiatric hospital in Guangzhou. Bei jingshenbing became her main area of concern as a practising lawyer. One Chinese anthropologist argued that Shenzhen was known for its run-away style of capitalism. The pursuit of self-interest there has been legitimised in public life. Citizens in the new city may be the first to meet the challenge of establishing a new moral practice of social compassion and volunteerism. ${ }^{53}$ The EJI chose Shenzhen as its base for the same reason. Instead of being registered as a typical government-organised NGO in China, the EJI was registered as a private culture and communication company, freeing it from any possible government meddling. Positioning itself as a professional legal consultation company, the EJI's strategy is different from that of activists who tend to disclose the socially unjust events related to psychiatric confinement, despite these like-minded civil rights defenders (weiquan renshi) being well informed about one another and their activities. The EJI emphasises its own professionalism while evaluating cases of unjust psychiatric admissions and proposing content for the Mental Health Law. It aspires to benchmark the kernel of the Convention on the Rights of Persons with Disabilities (CRPD), an international human rights treaty signed by the United Nations in 2004 with China's official endorsement. ${ }^{54}$

Although it once served as a shelter for victims of bei jingshenbing, the EJI can now be viewed as the fifth branch of science policymaking. According to EJI Director Huang Xuetao, within one year the EJI's objectives were written into the finalised version of the Mental Health Law, including the deletion of phrases which included 'lacking selfawareness', 'disturbing the public order', and 'hindering treatments if not hospitalised' in

\footnotetext{
52 In this paper, six interviews with EJI members and its service users are presented.

53 Jing Jun, 'From commodity of death to gift of life', in Kleinman (ed.), op. cit. (note 12), 78-105.

${ }^{54}$ Liu Jiajia, interviewed by the author, 5 February 2013, Shenzhen, China.
} 
the definition of mental patients. ${ }^{55}$ In doing so, all psychiatric treatment became based on the patients' own consent, thereby elevating the threshold of involuntary treatment. The new law has given patients 'the right to refuse admissions and the right to sue hospitals', increasing the protective right among users of psychiatric services. ${ }^{56}$ In addition, EJI members established online forums to assist the establishment of several self-advocacy groups such as the CNUSP. These groups have formed discussion platforms on the Internet and published anonymous reports documenting the personal experiences of psychiatric admissions. ${ }^{57}$ It can be argued that these groups' 'moral careers' commenced after they left the psychiatric institutions. These individuals - whom I call 'outmates' as a reference to the asylum inmates analysed in Goffman's classic account - not only defend themselves but also form alliances with individuals suffering from similar experiences in order to strengthen their quest for justice, science and morality.

Twenty-three-year-old Li Shije, for example, was sent to a psychiatric institution by his parents in 2011 after becoming involved in a quarrel with a restaurant manager over an air conditioning issue. Unsatisfied with the manager's attitude, Li called the police, who transferred their responsibility to Li's parents. Li and his parents had experienced tension since $\mathrm{Li}$ was a teenager. His father, who had been sent to the laogai (reform through labour) during the Cultural Revolution, had long considered Li's 'righteous' and 'pioneering' thoughts to be 'extreme' and 'paranoid'. Li was hospitalised in Shaoguan Veteran's Hospital for ninety-six days without undergoing any diagnostic interview. With the assistance of EJI, Li was able to find a lawyer. In 2014, a local court accepted and began to hear his case. $\mathrm{Li}$ is currently assisting another individual, still under admission to a mental hospital in another province, to prepare for a lawsuit. ${ }^{58}$

Similarly, the police admitted petitioner Wu Chunxia to the Henan Provincial Psychiatric Hospital in April 2008, when she travelled to Beijing to petition the All-China Women's Federation for help with an abusive marriage. Three months later, she was seized from her divorce hearing by police and detained for ten days. Local authorities sentenced her to one year of 're-education through labour' without trial. However, she was instead detained at a psychiatric hospital in Xinxiang City, Henan, where she was treated as a paranoid schizophrenic and hospitalised for 132 days. After she was discharged, Wu filed a lawsuit against the police for illegally detaining her after she was sent to a mental hospital with no psychiatric tests conducted. With the help of the EJI, she revealed in various oral and written accounts that, while she was at the hospital, electroconvulsive therapy was administered three times a week and she was force-fed drugs that caused weight gain, high blood pressure and other health problems. With an unofficial diagnosis of paranoia,

\footnotetext{
55 See Supplementary Provisions in H. H. Chen et al., 'Translated and annotated version of China's new Mental Health Law' in Shanghai Archives of Psychiatry, 24, 6 (2012), 305-19. Article 83 states: 'Conditions considered mental disorders in this law can be the result of a variety of causes; they are disturbances or abnormalities of perception, emotion, thinking or other mental processes that lead to significant psychological distress or to significant impairments in social adaptation or in other types of functioning. . . . [These conditions] are mental disorders characterized by severe symptoms that result in serious impairments in social adaptation or in other types of functioning, in impaired awareness of objective reality or of one's medical condition, or in an inability to deal with one's own affairs' (p. 316).

56 Equity and Justice Initiative, 'Mental Disability Rights', in Equity and Justice Initiative (ed.) (Shenzhen: Equity and Justice Initiative, 2013).

57 A-Li, 'Chinese Psychiatry Experience Report', in Chinese Network for Users and Survivors of Psychiatry (ed.) (CNUSP, 2013).

${ }^{58}$ Li Shijie, interviewed by the author, 25 July 2014, Dongguan, China. The interviewee agreed for his real name to be published.
} 
her symptoms were recorded as 'running around and petitioning for three years'. Her eyes were usually covered as she was forced to take pills, the purposes of which were kept from her. As seen in cases of other individuals, she observed that 'the harder I tried to prove I was normal, the more they said I was actually sick. ${ }^{59}$ After she won the lawsuit in May 2013, the defendants appealed against the judgement. The municipal court deliberately procrastinated on administering the second judgement. During that time, Wu Chunxia studied and became a self-educated expert in tort law and basic psychiatric knowledge. In May 2014, she finally won a verdict from the Henan High People's Court, which issued a final adjudication on the case. This example has encouraged many people who have suffered similar experiences to take action.

Another example shows not only the 'patient power' of erroneously diagnosed individuals, but also the participatory knowledge involved in the popular understanding of modern psychiatry and the mental health system in China. Unlike Steven Epstein's analysis in Impure Science (which analysed the ways in which HIV patients transformed themselves from a disease constituency into an alternative basis of expertise through self-education about the authority's drug approval policy and government lobbying), bei jingshenbing individuals do not label themselves activists. Instead, although they are defending their own rights, they actively seek to reinforce and maintain their professional appearance. Lily (anonym), who was deliberately diagnosed as suffering from 'acute temporary psychosis' after she became intoxicated while working at a chemical company in Zhenjiang in April 2007, accused the hospital of forging her family's signature and her own patient records to legitimise her unsuitability for work after she was subsequently fired that May. From 2007 to 2013, she actively participated in self-help networks online and otherwise, while suffering from the after-effects of wrongly prescribed psychiatric medication. On 10 October 2013, World Mental Health Day, Lily compiled four personal experiences of unjust psychiatric admission and published a report consisting of four parts: basic psychiatric knowledge, legal concerns about the Chinese mental health system, selfhelp strategies during admission crises and the predicament of current lawsuits. In the preface, Lily notes that the report was written to coincide with the annual theme defined by the National Health and Family Planning Commission of the People's Republic of China: developing professions, regulating services and defending patients' rights. ${ }^{60}$ In 2014, she changed her name to establish a self-advocacy group for people living with common mental disorders in Shanghai.

The growth of civil society also accelerated the formation of bei jingshenbing as a buzzword in public discourse. For example, Minsheng Guancha ('Monitor of People's Right to Live'), a website maintained by a retired schoolteacher, began collecting narratives of those who had experienced bei jingshenbing and posted them online. Since 2007, the website maintainer has uploaded more than 200 video clips related to various incidents of social injustice and psychiatric confinement to YouTube. ${ }^{61}$ Despite the Chinese government's widespread and subtle control of the Internet, such websites have managed to form a parallel online minjian (civil society) outside of China's Internet

\footnotetext{
${ }^{59} \mathrm{Wu}$ Chunxia, interviewed by the author, 3 August 2014, Ghuanzhou, China. The interviewee agreed for his real name to be published.

${ }^{60}$ Lily (name changed) et al. (2013), 'Chinese Psychiatry Experience Report', in Chinese Network for Users and Survivors of Psychiatry (ed.) (CNUSP).

${ }^{61}$ Minsheng Guancha. https://www.youtube.com/user/msguancha [accessed 12 May 2015].
} 
domain. ${ }^{62}$ Different organisations implement various strategies to give prominence to similar issues. Their activities reflect the growing, but dissimilar, degree of momentum of the civil participation of Chinese citizens in civil society, and their civil activism has encouraged various medical-knowledge-making patterns. Yet, in the absence of professional input, the hostile rhetoric against psychiatry these groups adopt, such as calling themselves 'victims of psychiatry', may be hampering dialogue with psychiatric experts and policymakers. Although the EJI has claimed that the essence of the CRPD has successfully been integrated into the final version of the Mental Health Law, the prohibition of psychiatric hospitalisation against a patient's free will has made psychiatric treatment more difficult, and the law has failed to specify the length of detention during a crisis intervention period. ${ }^{63}$

\section{Bei Jingshenbing 'From Above': Contrasting Tones Set by Chinese Psychiatrists}

According to Roy Porter, when documenting sufferers' voices, one must avoid 'turning the idylls of the sick into one long bellyache, a primal scream against the atrocities perpetrated by Nature and by social oppression' so as not to romanticise the suffering. ${ }^{64}$ Yet, also, one must not vilify the psychiatric community. Indeed, according to Chinese psychiatrists, efforts have been made to draft the Chinese national Mental Health Law for the past two decades. Similarly, since the 1990s, laws administered in different cities have secured various extents of protective rights for mental patients. ${ }^{65}$ The new Mental Health Law administered in May 2013 represents the state's legal intervention into various misuses of psychiatry.

According to medical historian Yang Nianqun, the transformation of modern medical services from policing space to medical space in China requires the professionalisation of medical disciplines and the support of the state. ${ }^{66}$ In the case of Chinese psychiatry, after a rapid development (which followed a long period of suspension during the $1960 \mathrm{~s}$ and 1970s), the comprehensive professionalisation of psychiatric disciplines at the state level remains a great challenge. In distinction to external assistance such as the World Health Organisation, the government itself established plans of various scales for reform of psychiatry as a specialised medical discipline and mental health system, after its early attempt in the early 1980 s. ${ }^{67}$ Even among medical professionals, psychiatrists of various generations have diverse views with regard to the causes of bei jingshenbing and the implementation of the Mental Health Law. For example, former Director of the Institute of

62 Jack L. Goldsmith and Tim Wu, Who Controls the Internet?: Illusions of a Borderless World (New York: Oxford University Press, 2008), xvi; Yongming Zhou, Historicizing Online Politics: Telegraphy, the Internet, and Political Participation in China (Stanford: Stanford University Press, 2006), xi.

63 See Yang Shao and Bin Xie, 'Operationalizing the Involuntary Treatment Regulations of China's New Mental Health Law', Shanghai Archives of Psychiatry, 26, 6 (2013), 384-6. Michael Phillips et al., 'China's New Mental Health Law: Reframing Involuntary Treatment', American Journal of Psychiatry, 170, 6 (2013), 588-91.

${ }^{64}$ Roy Porter, 'The Patient's View: Doing Medical History from Below', Theory and Society, 14, 2 (1985), 175-98.

65 They include the Protective Law of the Disabled (passed in 1990), Shanghai Act of Mental Health Management (passed in 2002) and Hangzhou Mental Health Act (passed in 2005).

${ }^{66}$ Nianqun Yang, 'Control of life and death and the transformation of space in early republican Beijing', in Nianqun Yang (ed.), Space, Memory and the Transformation of Society (Shanghai: Shanghai People's Publishing House, 2001).

${ }^{67}$ Tsung-Yi Lin and Leon Eisenberg, Mental Health Planning for One Billion People: A Chinese Perspective (Vancouver: The University of British Columbia Press, 1985). Also see Huang et al., op. cit (note 40). 
Mental Health of Peking University and Founding President of the Chinese Psychiatrists' Association, Yu Xin, praises the newly administered Mental Health Law; he believes it represents the Ministry of Health's reclamation of psychiatric patient management from the internal affairs sector. ${ }^{68}$ Mental Health Law task force member, leader of psychiatric specialist training and current President of the Chinese Psychiatrists' Association, Tang Hongyu, emphasises that the EJI does not facilitate the principle of patient autonomy in terms of psychiatric admission. In fact, he observes that this principle has existed in Mental Health Law drafts since the 1990s, but never made it into print. He also claims that the passing of the Mental Health Law would not result in substantial changes being made to patients' rights, as the laws in China have always been notoriously prescriptive and poorly enforced. ${ }^{69}$ As for senior psychiatrist and psychotherapist Xu Youxin, who was trained in the early 1950s, he notes that despite possible incidents of psychiatric abuse, the problem of bei jingshenbing is caused by various interpretations of psychiatric terms informed by cultural dissimilarity, and remains a complex matter. ${ }^{70}$

The conflicting interests among the individuals and institutions involved in mental health law-making and its related issues reveal another aspect of medical modernity: the structured differentiation of professions in modern society. For example, a tug-of-war has developed between EJI affiliates and psychiatric professionals over the management of involuntary treatment. One month after the EJI published its critical analysis of China's involuntary commitment system, the Chinese Psychiatrist Association published six press releases defending its professionalism and ethical conduct. ${ }^{71}$ As the judicial system, psychiatric disciplines, social work networks and civil society solidify, it is believed that such conflicts will become fiercer and require a stronger consultation mechanism for the stakeholders involved.

\section{Conclusion: Bei Jingshenbing, Chinese Modernity and the Co-Production of Psychiatric Knowledge}

At the end of August 2014, I was sitting at another gathering of the CNUSP in Guangzhou with all of the aforementioned individuals who had labelled themselves either users or survivors of Chinese psychiatric services. Also present were individuals and groups who had travelled there from Hangzhou, Kunming, Shanghai, Hong Kong and other cities throughout China. These were mostly self-advocacy groups acting in the interests of the mentally ill, as experiencers of bei jingshenbing have become the minority in these gatherings. The EJI's initiative had clearly shifted from defending the rights of selfidentified victims of psychiatry to promoting the rights of actual mental patients.

As Nancy Chen argues, the development of psychiatry in China has involved a series of translingual practices. The lingo and jargon related to psychiatry in this country are neologisms inextricably linked to the contexts of translation in which the learnings and practices of psychiatry are adopted and implemented. ${ }^{72}$ The translation process has not

68 Yu Xin, interviewed by the author, 18 June 2014, Beijing, China.

69 Tang Hongyu, interviewed by the author, 19 June 2014, Beijing, China.

${ }^{70} \mathrm{Xu}$ Youxin, interviewed by the author, 19 June 2014, Beijing, China.

${ }^{71}$ Chinese Psychiatrist Association, 'Medical Ethics', http://www.cpa-pa.org.cn/news/jsklist_c0605_..html, accessed 31 January 2014.

72 For example, asylum (fengyuan疯院), psychiatric institution (jingshenke bingyuan 精神科病院), mental hygiene (jingshen weisheng 精神卫生) and mental health (jingshen jiankang 精神健康). See Chen, op. cit. (note 13). 
been based solely on western theories, and should be viewed as an integral process of subject-making and state building. Therefore, bei jingshenbing should be seen as but another neologism in China's experience of modernity. As was the case during the centurylong development of modern psychiatry, there is a perpetual struggle between the 'dual role' ethical representation of psychiatry as either a coercive intervention of citizens' unwanted behaviour or a humane treatment for actual mental disorders. ${ }^{73}$ The coalition between state building and mental health in China has long been concerned with two standing issues: providing adequate care for a large population and maintaining social order.

In the late twentieth century, concerns about Chinese psychiatry and mental health related mostly to whether research carried out in cities could be translated into nationwide policies and whether the growing profit-oriented medical care would eventually result in the neglect of underprivileged citizens. ${ }^{74}$ In addition to these concerns, a new problem appeared in contemporary China: the confinement of 'normal' people in psychiatric institutions. This study has explored the reasons behind this issue. In the process, it encountered two main challenges: first, the difficulty of proving that those who were considered mentally ill were actually sane. These cases reflect the complexity and intersubjectivity of 'madness' definitions among the transforming cultural, legal and medical realms in historical and contemporary China. This is precisely why, within the past two years, the CNUSP managed to transform itself from a victim group into a self-advocacy network in alliance with actual psychiatric patients. The second challenge is that it difficult to generalise the bei jingshenbing situations, as the cases reported in the media have been sporadic. At present, although the number of psychiatric beds has doubled and the Mental Health Law has been implemented at the national level, the degrees of diversity and inequality in society clearly cannot be reduced to a social mechanism managed through the science of social statistics, which Roy Porter emphatically relates to the terra firma of the material conditions of healthy and sick communities. ${ }^{75}$ The voices collected here also reflect the quest of modern citizens to achieve autonomy and individuality against the overwhelming social force, historical legacy, alien culture and new technology behind bei jingshenbing. This unique experience of medical modernity in post-socialist China could be seen as a phenomenon of 'co-production' of medical knowledge, to borrow Steven Epstein's expression.

Discussing the problem of suicide in China, social anthropologist Wu Fei has coined the term 'incomplete modernity' to denounce the generally biased view of the sluggishness of China's modernisation. He believes that the mental problems of Chinese people emerged along with the moral conflicts and emotional struggles produced by China's rapid and drastic modernisation. ${ }^{76}$ This also becomes relevant in the case of bei jingshenbing. In another context, when exploring the relationship between medicine and modernity, historian Roger Cooter has delineated the space sandwiched between 'medicine in modernity' and 'modernity in medicine' that reflects the source of acrimony, anxiety and

${ }^{73}$ For example, See Michael D. Robertson and Garry Walter, 'Many faces of the Dual-role Dilemma in Psychiatric Ethics', Australian and New Zealand Journal of Psychiatry, 42 (2008), 228-35.

74 Pearson, Mental Health Care in China; Michael R. Phillips, 'The Transformation of China's Mental Health Services', The China Journal, 39 (1998), 1-36.

75 Roy Porter, 'Shaping Psychiatric Knowledge: The Role of the Asylum', Clio Medica, 29 (1995), 255-73.

${ }^{76}$ For Wu, the term 'incomplete modernity' was created to contrast the 'incomplete tradition', referring to the various layers of power struggle encountered by suicidal patients and particularly their pursuit of justice in Chinese family politics. See Wu, 'Suicide, a Modern Problem in China', op. cit. (note 12). 
debates over time instead of merely tracing innovations and elusively challenging the status of health and diseases formalised by institutions and medical authorities. ${ }^{77}$ This space is where all vignettes presented in this paper are located.

As Sheila Jasanoff has noted, the construction of scientific knowledge is highly political and culturally specific. One must closely examine and challenge how professional knowledge is introduced, influenced, defined and interpreted in terms of its social and political backgrounds, agenda and local applications. ${ }^{78}$ Moreover, the politics of public rationality shaped by ungoverned forms of reason can safeguard the abuse of power. Citing the example of the regulatory politics of environmental sciences in the United States, Jasanoff observes that scientific advisers became the fifth branch of policymaking sectors. ${ }^{79}$ According to her, a co-production framework that involves scientific policymaking enables one to think about power and highlights the often invisible role of knowledge, expertise, technical practices and material objects in shaping, sustaining, subverting or transforming authority relations. The complex stories of bei jingshenbing bring these issues to the fore.

\footnotetext{
${ }^{77}$ Roger Cooter, 'Medicine and modernity', in Mark Jackson (ed.), The Oxford Handbook of the History of Medicine (Oxford; New York: Oxford University Press, 2011), 100-16.

78 Jasanoff, op cit. (note 5).

79 Sheila Jasanoff, The Fifth Branch: Science Advisers as Policymakers (Cambridge, MA: Harvard University Press, 1990), xiii.
} 